\title{
O Ciclo de Políticas Públicas para o enfrentamento da exploração sexual comercial de crianças e adolescentes nos Municípios Brasileiros
}

\author{
The Cycle of Public Policies to face sexual commercial \\ exploitation of children and adolescents in Brazilian \\ Municipalities
}

\author{
Rafael Bueno da Rosa Moreira ${ }^{1}$ \\ Rafaela Preto de Lima ${ }^{2}$
}

\begin{abstract}
RESUMO
A exploração sexual comercial de crianças e adolescentes é ao mesmo tempo uma das piores formas de trabalho infantil e uma modalidade de violência sexual, consistindo numa violação de direitos a ser enfrentada no território nacional. O objetivo geral da pesquisa é analisar a realização do ciclo de políticas públicas para o enfrentamento da exploração sexual comercial de crianças e adolescentes nos municípios brasileiros. Para tanto, os objetivos específicos são: demonstrar a proteção jurídica contra a exploração sexual comercial de crianças e adolescentes no Brasil; contextualizar as principais características da exploração sexual comercial de crianças e adolescentes; e traçar o ciclo de etapas de políticas públicas de enfrentamento da exploração sexual comercial de crianças e adolescentes no Sistema de Garantia de Direitos e na Rede de Atendimento dos municípios. O problema que orienta a pesquisa é como devem ser executadas as políticas públicas de enfrentamento da exploração sexual comercial de crianças e adolescentes nos municípios brasileiros? O método de abordagem é o dedutivo, que parte da verificação das premissas gerais sobre o tema e vai especificando, e os métodos de procedimento são o monográfico e o estatístico. Utiliza-se das técnicas de pesquisa bibliográfica, com embasamento em livros, artigos científicos, teses e dissertações, e estudo de caso factual, apresentando-se indicadores coletados em estudos sobre o tema. Constata-se que a exploração sexual comercial de crianças e adolescentes deve ser enfrentada por meio da
\end{abstract}

\footnotetext{
1 Pós-doutorando no Programa de Pós-Graduação em Direito da Universidade de Santa Cruz do Sul - Unisc, Doutor em Direito com Bolsa Prosuc Capes Modalidade II e Mestre em Direito pela Universidade de Santa Cruz do Sul (UNISC), integrante do Grupo de Estudos em Direitos Humanos de Crianças, Adolescentes e Jovens (GRUPECA/UNISC) e do Grupo de Pesquisa Políticas Públicas de Inclusão Social (UNISC). Professor do Curso de Graduação em Direito do Centro Universitário da Região da Campanha - URCAMP/Bagé e Coordenador do Grupo de Pesquisas sobre Direitos Humanos e Políticas Públicas para Crianças e Adolescentes (GEDIHCAURCAMP). Endereço eletrônico: rafaelbmoreira2@yahoo.com.br.

2 Bacharel em Direito no Centro Universitário da Região da Campanha - URCAMP/Bagé. Advogada. Integrante do Grupo de Pesquisas sobre Direitos Humanos e Políticas Públicas para Crianças e Adolescentes (GEDIHCA/ URCAMP). Foi bolsista de Iniciação Científica do Programa Institucional de Iniciação Científica - PIIC da URCAMP, integrando o Projeto de Pesquisa sobre Violência Intrafamiliar contra Crianças e Adolescentes e Políticas Públicas e o Projeto de Extensão sobre Trabalho Infantil e Políticas Públicas para o seu Enfrentamento no Município de Bagé-RS, vinculados ao curso de Direito da URCAMP. Endereço eletrônico: rafaelapretodelima@gmail.com.
} 
execução de etapas cíclicas de políticas públicas previamente traçadas e que são direcionadas pelas características de cada município.

\title{
PALAVRAS-CHAVE:
}

Exploração sexual comercial; criança e adolescente; políticas públicas; violência sexual; trabalho infantil.

\begin{abstract}
The commercial sexual exploitation of children and adolescents is at the same time one of the worst forms of child labor and a form of sexual violence, consisting of a violation of rights to be faced in the national territory. The main objective of this paper is to analyze the implementation of the public policy cycle to face the commercial sexual exploitation of children and adolescents in Brazilian municipalities. In order to solve the presented problem, the specific objectives are: to demonstrate legal protection against commercial sexual exploitation of children and adolescents in Brazil; contextualize the main characteristics of commercial sexual exploitation of children and adolescents; and to outline the cycle of stages of public policies to confront commercial sexual exploitation of children and adolescents in the Rights Guarantee System and in the Municipalities' Service Network. The guiding problem of this research is the analysis on how public policies should be applied in order to confront commercial sexual exploitation of children and adolescents in Brazilian municipalities be implemented. The approach method is the deductive one, which starts from the verification of the general premises on the theme and specifies it, and the procedural methods are monographic and statistical. Bibliographic research techniques are used, based on books, scientific articles, theses and dissertations, and a factual case study, presenting indicators collected in studies on the topic. As a result, the commercial sexual exploitation of children and adolescents must be faced through the execution of cyclical stages of public policies previously outlined and that are guided by the characteristics of each municipality.
\end{abstract}

\section{KEYWORDS:}

Commercial sexual exploitation; child and adolescent, public policies; sexual violence; child labor.

\section{INTRODUÇÃO}

A exploração sexual comercial é uma modalidade de violação de direitos de crianças e adolescentes que vem ocorrendo de forma continuada no Brasil. Pode-se asseverar que ela, ao mesmo tempo, é um tipo de violência sexual e uma das piores formas de trabalho infantil. A execução de ações de políticas públicas visando sua prevenção e erradicação é um dos desafios 
para a concretização dos direitos da criança e do adolescente, o que deve ocorrer no âmbito dos municípios do país e atentando para as peculiaridades de cada localidade.

A investigação científica foi delimitada na identificação das etapas cíclicas que devem ser percorridas para a estruturação das políticas públicas de enfrentamento da exploração sexual comercial de crianças e adolescentes nos municípios brasileiros, tendo como base o marco teórico da proteção integral.

O objetivo geral da pesquisa é analisar a realização do ciclo de políticas públicas para o enfrentamento da exploração sexual comercial de crianças e adolescentes nos municípios brasileiros. Com tal finalidade, os objetivos específicos estabelecidos e cumpridos em cada subdivisão do artigo científico, são: demonstrar a proteção jurídica contra a exploração sexual comercial de crianças e adolescentes no Brasil; contextualizar as principais características da exploração sexual comercial de crianças e adolescentes; e traçar o ciclo de etapas de políticas públicas de enfrentamento da exploração sexual comercial de crianças e adolescentes no Sistema de Garantia de Direitos e na Rede de Atendimento dos municípios.

A abordagem do tema possui por justificativa a necessidade do aperfeiçoamento da execução de políticas públicas para o enfrentamento da exploração sexual comercial e, consequentemente, a efetivação dos direitos humanos da criança e do adolescente. A explanação sobre a proteção jurídica contra o problema, o conhecimento sobre as principais características do tema e a apresentação das etapas do ciclo que devem ser percorridos pelas políticas públicas são relevantes para gerar aportes de contribuições no campo jurídico, político, social e acadêmico, proporcionando embasamentos para ações práticas contra a exploração sexual comercial de crianças e adolescentes que vêm sendo consolidados pelos resultados publicados pela comunidade científica nacional e internacional.

Como problema de pesquisa, utilizou-se: como devem ser executadas as políticas públicas de enfrentamento da exploração sexual comercial de crianças e adolescentes nos municípios brasileiros?

A hipótese inicial para a resolução do problema estabelece que o Brasil consolidou a proteção jurídica contra a exploração sexual comercial de crianças e adolescentes, cumprindose importante passo, entretanto, os indicadores e estudos demonstram a continuidade da 
ocorrência de tal violação de direitos em diversos municípios do país, o que se dá mediante as mais diversas características. Para o seu enfrentamento de forma efetiva, faz-se necessário a execução de etapas cíclicas de políticas públicas previamente traçadas que devem ser percorridas intersetorialmente no âmbito de cada município.

O método de abordagem é o dedutivo, que parte da verificação das premissas gerais sobre o tema e vai especificando, e os métodos de procedimento são o monográfico e o estatístico. Utiliza-se das técnicas de pesquisa bibliográfica, com embasamento em livros, artigos científicos, teses e dissertações, que foram coletadas no portal Google Acadêmico e no Banco de Teses e Dissertações da Capes, e estudo de caso factual, o que proporcionou a apresentação de indicadores coletados em estudos sobre o tema e bases de dados.

\section{PROTEÇÃO JURÍDICA CONTRA A EXPLORAÇÃO SEXUAL COMERCIAL DE CRIANÇAS E ADOLESCENTES}

A proteção jurídica aos direitos da criança e do adolescente frente à exploração sexual comercial se inicia desde o âmbito internacional, visto que a Organização Internacional do Trabalho (OIT) e a Organização das Nações Unidas (ONU) designaram compromissos em prol da erradicação do trabalho infantil e contra todos os tipos de violência sexual, o que engloba a exploração sexual comercial como uma de suas modalidades. É nas Assembleias Gerais, com representações dos Estados-Membros, que são definidas as convenções internacionais, as quais visam estimular a garantia de forma universal dos direitos da criança e do adolescente. Destacase que o ordenamento jurídico brasileiro foi influenciado positivamente por essas convenções, o que ocorreu a partir das suas ratificações, gerando-se avanços na área do Direito da Criança e do Adolescente.

Na dimensão internacional, a referência normativa universal de proteção aos direitos da criança e do adolescente é a Convenção sobre os Direitos da Criança da ONU, instituída em 20 de novembro de 1989 em sua Assembleia Geral. Nela, estabeleceu-se garantias fundamentais a fim de consolidar as crianças e adolescentes como sujeitos titulares de direitos, num período que ficou caracterizado pela mobilização internacional de proteção à infância (ONU, 1989). 
O Brasil ratificou tal Convenção em 21 de novembro de 1990, pelo Decreto n. 99.710, determinando bases estruturantes para a proteção jurídica efetiva aos direitos da criança e do adolescente. A convenção teve papel importante em vincular a obrigação de promulgação da legislação interna sobre o assunto no Brasil, bem como por estimular a estruturação, criação e execução de políticas públicas com a finalidade de cumprir o definido juridicamente em várias dimensões (ONU, 1989).

Com isso, destaca-se que o documento internacional mais relevante no tocante aos direitos da criança e do adolescente é a Convenção sobre os Direitos da Criança da ONU (VERONESE, 2015b, p. 127).

As convenções internacionais se caracterizam por influenciar positivamente o ordenamento jurídico nacional de cada Estado, gerando com isso reações benéficas no desempenho de políticas públicas de acordo com as incumbências firmadas na esfera internacional (REIS, 2010, p. 152).

A Convenção sobre Direitos da Criança da ONU institui uma listagem de direitos humanos, aos quais devem ser garantidos de maneira universal e sem qualquer distinção, tendo como objetivo assegurar o desenvolvimento integral humano referente à infância, o que constitui a formação mental, física, social, intelectual e cultural. Ressalta-se, dentre os artigos elencados, os direitos: à dignidade; à vida; à liberdade; à saúde física e mental; à igualdade; à segurança; à proteção contra a transferência ilegal para o exterior, contra todas as formas de violência física ou mental, bem como contra todas as formas de exploração econômica e sexual; ao acesso à informação; ao bem-estar social, moral e espiritual; à reputação e à honra; à educação; ao lazer e ao descanso; à participação da vida artística e cultural (ONU, 1989).

A sistematização da erradicação da exploração sexual comercial de crianças e adolescentes tem por finalidade o impedimento dos impactos negativos que são acarretados com essa prática no período geracional da infância, o que causa a violação de direitos que estão conjecturados na convenção em análise e que são indispensáveis ao desenvolvimento integral da pessoa humana (ONU, 1989).

A comunidade internacional vem progredindo, uma vez que obriga que os Estados possibilitem o reconhecimento, promoção e proteção dos tratados internacionais que discorram 
sobre direitos humanos, certificando que quaisquer violações não serão matéria, tão somente, de alçada interna. Sendo assim, cada Estado possui o compromisso de proteger os direitos humanos, contudo, em se tratando de violações, a questão caberá a toda comunidade internacional (GORCZEVSKI, 2009, p. 150-151).

No momento da ratificação da Convenção sobre os Direitos da Criança da ONU, os Estados assumem o compromisso de proteção e garantia aos direitos da criança e do adolescente, estipulando-se o dever de execução de políticas públicas com o objetivo de efetivação da proteção dos direitos humanos acordados internacionalmente e que se tornam parte do ordenamento jurídico interno (ONU, 1989).

A Convenção sobre os Direitos da Criança da ONU estabeleceu que os Estados-Partes invistam em políticas públicas que proporcionem “[...] melhores condições de vida, melhores condições de desenvolvimento, sadio e harmonioso, e que zelem pelo cumprimento integral dos direitos inerentes à fase da infância [...]” (LIMA, 2017, p. 91).

O artigo 34 da Convenção sobre os Direitos da Criança da ONU disciplina contra a exploração sexual comercial de crianças e adolescentes, determinando que os EstadosMembros desenvolvam políticas públicas para a extinção de todas as formas de violência sexual no período da infância. Há o compromisso de realização de ações de políticas públicas que ofereçam todas as providências necessárias para a inclusão social e recuperação física e psicológica das crianças e adolescentes que forem vitimadas pela exploração sexual comercial ou outra modalidade de violência sexual (ONU, 1989).

Os Estados signatários, de acordo com o artigo 19 da Convenção, apresentam encargos em produzir medidas interdisciplinares, tanto legislativas, como administrativas, educacionais e sociais, com intento de proteção de crianças e adolescentes frente a todos os meios de violência física ou mental (ONU, 1989).

A obrigatoriedade em oferecer medidas de proteção à saúde e à assistência social está disciplinada no artigo 39, almejando a recuperação psicológica, física e a inclusão social de crianças e adolescentes que tiveram seus direitos violados em razão da exploração sexual comercial ou demais formas de violência (ONU, 1989). 
A promoção de direitos humanos não pode ser traçada de maneira isolada das ações estratégicas de políticas públicas. As interpelações políticas acerca da pauta de direitos humanos nunca devem estar em segundo plano, pois a ideia central carece de reconhecimento por meio das políticas públicas (FLORES, 2009, p. 73).

A proteção aos direitos da criança e do adolescente também vem sendo convencionada pela OIT. Em sua Convenção n. 138 de 1973, que é suplementada pela Recomendação 146, está determinada a idade mínima para o labor, a fim de que não haja danos ao desenvolvimento integral de crianças e adolescentes. Estabeleceu-se aos Estados-Partes a necessidade de criar ações estratégicas de políticas públicas para a erradicação de qualquer forma de trabalho infantil, incluindo-se a exploração sexual comercial de crianças e adolescentes. O Brasil, após passar por um processo de readequação da legislação interna, ratificou a Convenção no dia 28 de junho de 2001 (OIT, 1973).

A consolidação e a estruturação do Direito da Criança e do Adolescente no Brasil teve importante influência do direito internacional, iniciando-se a partir das ratificações da Convenção sobre os Direitos da Criança da ONU e, posteriormente, das Convenções 138 e 182 da OIT. A proteção jurídica dos direitos da criança e do adolescente foi sustentada por essas Convenções, as quais também propiciaram a criação de políticas públicas intersetoriais (MOREIRA; CUSTÓDIO, 2018, p. 195).

A Convenção n. 182 da OIT de 1999, foi ratificada pelo Brasil em 2 de fevereiro de 2000, ela abarcou a vedação das piores formas de trabalho infantil e a atuação imediata mediante a criação de ações prioritárias para a sua abolição, sendo complementada pela Recomendação n. 190. Ela visa a proteção de toda a pessoa com até dezoito anos de idade e conceitua as piores formas de trabalho infantil em seu artigo $3^{\circ}$, expondo na alínea " $\mathrm{b}$ " a exploração sexual comercial, que é: “[...] b) a utilização, o recrutamento ou a oferta de crianças para a prostituição, a produção de pornografia ou atuações pornográficas". Com isso, todos os Estados que a ratificarem, deverão elaborar as ações estratégicas de políticas públicas para o seu enfrentamento de maneira prioritária e com a maior urgência possível (OIT, 1999).

Além desses, foram pactuados outros documentos internacionais que orientam o combate à exploração sexual comercial de crianças e adolescentes, tais como: o Protocolo Facultativo à Convenção sobre os Direitos da Criança, referente à venda de crianças, à 
prostitução infantil e à pornografia infantil; o Protocolo Adicional à Convenção das Nações Unidas contra o Crime Organizado Transnacional Relativo à Prevenção, Repressão e Punição do Tráfico de Pessoas, em Especial Mulheres e Crianças; e a Declaração de Estocolmo.

O Direito da Criança e do Adolescente, no Brasil, está consolidado como um ramo jurídico autônomo, o qual foi constituído de acordo com a legislação internacional. A promulgação da Constituição da Repúbica Federativa do Brasil, em 1988, e as demais legislações infraconstitucionais, especialmente o Estatuto da Criança e do Adolescente, proporcionaram o rompimento com o modelo anterior, o qual fundamentava definições ultrapassadas e que iam de encontro a perspectiva de sujeitos de direitos, que é uma das sustentações da proteção integral dos direitos da criança e do adolescente.

A Constituição da República Federativa do Brasil realizou aportes significativos na estruturação dos direitos da criança e do adolescente em seu artigo 227, o qual determina a proteção integral, mediante uma relação de direitos e garantias que obrigatoriamente devem ser assegurados com prioridade absoluta e responsabilidade compartilhada entre família, sociedade e Estado. O artigo é fundamental para assegurar a condição de sujeito de direitos, objetivando a garantia do desenvolvimento humano integral, não violento e com respeito a condição característica de pessoa em desenvolvimento. Também se encontra estabelecido a previsão de punição de forma severa, no seu parágrafo $4^{\circ}$, a todas espécies de violência, abuso e a exploração sexual de crianças e adolescentes (BRASIL, 1988).

O artigo 227 tem eficácia plena e imediata, devendo ser reconhecido e respeitado na íntegra, servindo de fundamento para a interpretação do direito, assim como para a orientação da gestão e execução de políticas públicas. Esse artigo vem produzindo efeitos jurídicos a partir de sua promulgação, vinculando o Poder Público a tratar com prioridade a execução de políticas públicas que possuam como objetivo a efetivação dos direitos de crianças e adolescentes (SILVEIRA; VERONESE, 2017, p. 129-130).

Por sua vez, o inciso XXXIII, do artigo $7^{\circ}$, da Constituição da República Federativa do Brasil, determina a idade mínima inicial de dezesseis anos para o trabalho no Brasil, com exceção do trabalho noturno, perigoso e insalubre, que é necessário possuir no mínimo dezoito anos de idade, e a modalidade de aprendizagem, onde a idade mínima é de quatorze anos (BRASIL, 1988). 
Os direitos fundamentais, apesar de estarem assegurados em nível constitucional como de titularidade da universalidade de crianças e adolescentes, necessitam ser consolidados através de ações políticas (ROSSATO; LÉPORE, 2015, p. 136-141).

Salienta-se que, quanto à condição de acesso a direitos para crianças e adolescentes no Brasil: "o reconhecimento da condição de sujeito de direitos fundamentais é pressuposto da cidadania das pessoas, do pertencimento a sociedades, como a brasileira, pautada pelo processo institucional jurídico-político" (SANTOS; VERONESE, 2015, p. 167).

A estrutura do Direito da Criança e do Adolescente é fundada em regras e princípios característicos, que trouxeram progressos quanto as concepções anteriores. Com isso, as garantias propostas pela Constituição da República Federativa do Brasil e pelo Estatuto da Criança e do Adolescente estão de acordo e contemplam o princípio da progressividade dos direitos humanos, vedando-se qualquer regresso e/ou omissão de garantias já asseguradas como direitos fundamentais. Salienta-se que o direito da criança e do adolescente é considerado avançado por estabelecer: “[...] um sistema de garantias de direitos que impõe um conjunto de responsabilidades e ações para que os direitos proclamados sejam garantidos e efetivados no plano fático" (CUSTÓDIO, 2015, p. 7-11).

Há um rol de princípios que cumprem dever fundamental ao direito da criança e do adolescente, pois possuem funções características, contribuindo com o progresso sistêmico do ordenamento jurídico brasileiro. Eles são classificados teoricamente em concretizantes e estruturantes.

Os estruturantes são: o princípio do interesse superior da criança e do adolescente; o princípio da proteção integral; o princípio do caráter garantista; e o princípio da universalização (LIMA, 2001, p. 169-209). Eles compõem “[...] a 'estrutura pétrea' e, nessa condição, cumprem uma tarefa funcional de garantir o sentido geral, a unidade interna e a coerência lógica, sistemática, axiológica e teleológica do Direito da Criança e do Adolescente" (LIMA, 2001, p. 159). Já os concretizantes tem por objetivo a busca pela materialização dos princípios estruturantes, exercendo atribuições complementares à base do direito da criança e do adolescente, estando entre eles: o princípio da tríplice responsabilidade compartilhada; e o princípio da prioridade absoluta (LIMA, 2001, p. 162). 
Na proteção jurídica frente à exploração sexual comercial, o Estatuto da Criança e do Adolescente também exerceu função relevante determinando a proteção integral à criança e ao adolescente para reger esse ramo do direito e a sua legislação (BRASIL, 1990).

No seu artigo $4^{\circ}$ foi reiterado e expandido o artigo 227 da Constituição da República Federativa do Brasil, regulando direitos que são infringidos com a exploração sexual comercial de crianças e adolescentes, bem como abordando os princípios da proteção integral, da prioridade absoluta e da tríplice responsabilidade compartilhada (BRASIL, 1990).

É de acordo com o aparato jurídico constitucional e com as normas internacionais que surgiu o Estatuto da Criança e do Adolescente, ratificando-se o direito em condições dignas ao desenvolvimento físico, mental, moral, espiritual e social de crianças e adolescentes e a proibição a qualquer forma de violação de direitos (BAPTISTA; ZAMORA, 2019, p. 12).

A finalidade da proteção jurídica é garantir às crianças e aos adolescentes os direitos à saúde, à alimentação, à vida, à educação, ao esporte, à convivência familiar e comunitária, à dignidade, à profissionalização, à liberdade, ao respeito, à cultura, ao lazer, à proteção contra o trabalho infantil e à proteção contra qualquer forma de violência, crueldade, opressão e discriminação. Ressalta-se que quando ocorre a exploração sexual comercial de crianças e adolescentes, há nitidamente a violação de vários desses direitos e garantias.

A garantia do direito de gozar do rol de direitos fundamentais, os quais são de titularidade da pessoa humana, está previsto no artigo $3^{\circ}$ do Estatuto da Criança e do Adolescente, concedendo-se, assim, condições dignas e de liberdade, tanto nas dimensões morais, físicas, sociais, espirituais e mentais, como, ainda, atentando-se para o princípio da prioridade absoluta em relação ao atendimento e desenvolvimento de todas as etapas das políticas públicas (BRASIL, 1990).

Já o artigo $5^{\circ}$ do Estatuto prevê a vedação de qualquer meio de violência, crueldade, discriminação, opressão, negligência e exploração, que infrinjam os direitos fundamentais, seja por ação ou omissão, abrangendo a exploração sexual comercial de crianças e adolescentes. Os direitos da criança e do adolescente são de caráter universal, ou seja, necessitam primar pelo preceito da não discriminação. Nesse sentido, faz-se necessário que não haja distinções decorrentes de qualquer condição de diversidade (BRASIL, 1990). 
É indispensável que a garantia aos direitos fundamentais de crianças e adolescentes seja reconhecida, para que assim, haja lugar para a realização de reivindicações em prol da concretização desses direitos nos espaços públicos, com a participação do Estado, da sociedade e da família, sendo essas entidades corresponsáveis entre si. Com isso, as ações de políticas públicas devem estruturar as iniciativas para a efetivação do acesso a direitos aos sujeitoscidadãos (CUSTÓDIO, 2008, p. 32).

A base teórica da proteção integral foi estabelecida através de ideias revolucionárias que visavam a interpretação do Direito da Criança e do Adolescente. Ela teve relevância na formação do Sistema de Garantia de Direitos da Criança e do Adolescente, tendo contado com espaço para criações democráticas pela participação popular. Estabeleceu estratégias de execução de políticas públicas, orientando as ações de forma intersetoriais, articuladas, descentralizadas e em rede. Assim, a teoria da proteção integral possui uma base resistente e que vem se fortalecendo, impossibilitando a prática de ideias retrocedentes e, cientificamente, já superadas (CUSTÓDIO, 2008, p. 31-32).

A criação de uma teoria para a infância oportuniza a concretização de uma estrutura a fim de transformar a realidade definida por formatos opressores. O desenvolvimento humano ocorre desde a concepção da vida até o acesso a fase adulta, tratando assim, de um ciclo de mutações em muitos sentidos. O começo da vida é na infância, porém é característico das relações, nesse período, a existência de negações, as quais, em uma análise pedagógica, são notadamente criticadas, devendo-se com isso, buscar uma "nova infância", definindo para ela a educação como o caminho mais apropriado (BUSTELO, 2011, p. 138-144).

A proteção quanto a idade mínima para o trabalho também foi prevista pela Consolidação das Leis do Trabalho, a partir do seu artigo 402, sendo referidas as limitações estatutárias e constitucionais, além da vedação do trabalho em lugares ou serviços negativos a sua moralidade conforme o artigo 405, inciso II e parágrafo $3^{\circ}$ (BRASIL, 1943).

O Decreto n. 6.481 de 2008 é decorrente da Convenção n. 182 da OIT, ele aborda a Lista das Piores Formas de Trabalho Infantil, a qual necessita ser reexaminada periodicamente através de consulta às organizações que representam trabalhadores e empregadores. $\mathrm{O}$ decreto indica a vedação aos trabalhos que são prejudiciais à moralidade; como também lista os 
trabalhos que configuram exploração sexual comercial de crianças e adolescentes, em variadas situações, e que precisam de execuções imediatas para a sua extinção (BRASIL, 2008).

E o Código Penal e o Estatuto da Criança e do Adolescente possuem dispositivos para a responsabilização penal dos sujeitos que exercerem alguma atividade relacionada com a exploração sexual comercial de crianças e adolescentes (BRASIL, 1940; BRASIL, 1990).

Observa-se que a OIT e a ONU, mediante suas declarações, recomendações, protocolos e convenções, influenciaram, positivamente, na proteção aos direitos da criança e do adolescente no Brasil, assim como vincularam o país a criar políticas públicas com o intuito de efetivar o determinado juridicamente. A estrutura para o combate à exploração sexual comercial de crianças e adolescentes se inicia no âmbito internacional e é solidificada no ordenamento jurídico interno brasileiro, pois existem instrumentos consideráveis em diversas legislações que objetivam a erradicação dessa exploração. Portanto, constata-se que o Brasil já possui uma base legal consolidada a fim de extinguir o problema, restando, como principal desafio, a efetivação das previsões jurídicas por meio do exercício de políticas públicas na esfera municipal, atentando-se para as especificidades de cada localidade.

\section{CARACTERÍSTICAS DA EXPLORAÇÃO SEXUAL COMERCIAL DE CRIANÇAS E ADOLESCENTES}

A exploração sexual comercial de crianças e adolescentes é concomitantemente uma das piores formas de trabalho infantil e um tipo de violência sexual. Trata-se de uma atividade de caráter pornográfico ou sexual, na qual ocorre a violação de direitos de crianças e adolescentes por meio de pagamentos com bens, dinheiro ou promessas, podendo, inclusive, realizar-se mediante ameaças. (MOREIRA, 2020, p. 77).

As causas da exploração sexual são inúmeras, variando de acordo com as peculiaridades de cada região, com influências do local em que as crianças e adolescentes frequentam, intervindo, ainda, fatores como as questões financeiras, sociais, culturais, étnico-raciais, geracionais, de gênero, de referências familiares e comunitárias, entre outros. Assim, não existe 
um rol extintivo de fatores que geram essa exploração, sendo um fenômeno de extrema complexidade (LONDOÑO, 2015, p. 250-252).

As causas dessa prática podem se subdividir em: culturais, que abarcam principalmente a coisificação da infância e o adultocentrismo; econômicas, referentes as situações de pobreza, desigualdade social, globalização e exclusão social; e, ainda, na carência de ações e estratégias de políticas públicas para o combate ao problema, que surge em virtude da ausência de capacitação e estrutura, bem como a falta de acesso a direitos. Assim, a exploração sexual comercial gera a violação de direitos fundamentais e resulta em diversas consequências negativas para o desenvolvimento integral de crianças e adolescentes (CUSTÓDIO; MOREIRA, 2015, p. 75-86).

Até serem sujeitadas à exploração sexual comercial, as crianças e adolescentes enfrentam as mais variadas formas de violação, negação ou privação de direitos, como o caso da evasão escolar, da extrema pobreza, dos diferentes tipos de violência, da fome, do abandono, da drogadição, entre outros. Em vista disso, em diversos casos, essa exploração, erroneamente, é considerada como o meio para alcançar maneiras de superar tais violações, de garantir autonomia e independência, e de suprir as necessidades básicas de consumo (ORDÓÑEZ; GONZÁLEZ, 2009, p. 1.016-1.021).

As rodovias são locais de incidência da exploração sexual comercial de crianças e adolescentes, pois vem sendo identificado que os caminhoneiros vêm buscando tais atividades. Salienta-se que a rotatividade rodoviária é peculiar dessa profissão, visto que há exigência de incessante circulação, uma vez que os caminhões são o principal meio de transporte de mercadorias. Com isso, identificou-se, em pesquisas realizadas pelo Programa Mão Certa, o percentual de motoristas entrevistados que afirmaram ter praticado atos sexuais com crianças e adolescentes: em 2005 - 36,8\%; em 2010 - 17,9\%; em 2015 - com caminhoneiros autônomos - 4,3\%; e 2015 - com caminhoneiros de empresas - 12,7\% (CERQUEIRA-SANTOS, 2015, p. 17). 


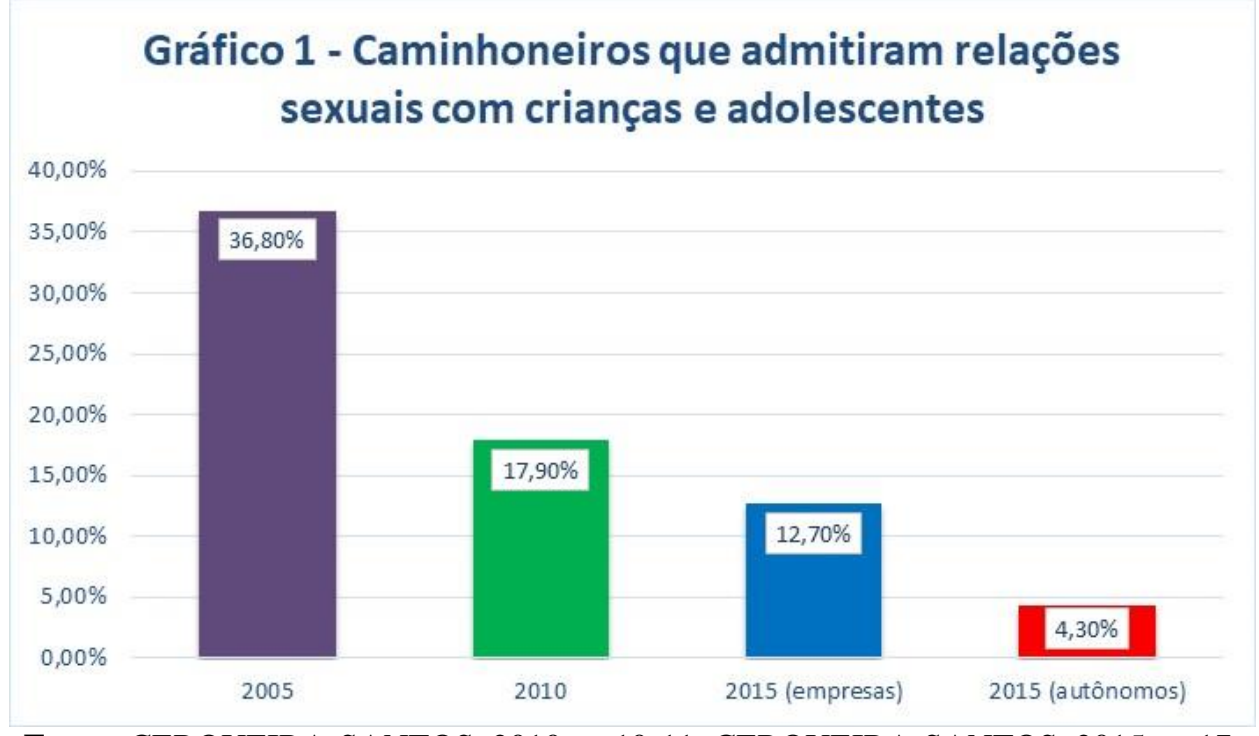

Fonte: CERQUEIRA-SANTOS, 2010, p. 10-11; CERQUEIRA-SANTOS, 2015, p. 17.

Nas entrevistas ocorridas nos anos de 2005, 2010 e 2015, os dados apurados nas amostras aleatórias são alarmantes, pois, quando questionados quesitos diversos, restou demonstrado que a exploração sexual comercial de crianças e adolescentes está presente de maneira substancial nas rodovias federais brasileiras e nos entornos de estacionamento (CERQUEIRA-SANTOS, 2015, p. 24).

\begin{tabular}{|c|c|c|c|}
\hline \multicolumn{4}{|c|}{ Tabela 1: Disponibilidade de sexo na estrada - Índices de respostas "SIM" } \\
\hline Questionário & $\mathbf{2 0 0 5}$ & $\mathbf{2 0 1 0}$ & $\mathbf{2 0 1 5}$ \\
\hline A prostituição é comum nos postos e estradas por onde ando & $99,2 \%$ & $98,5 \%$ & $95 \%$ \\
\hline $\begin{array}{c}\text { Em geral, meus colegas caminhoneiros saem com prostitutas } \\
\text { parceiras eventuais }\end{array}$ & $97,9 \%$ & $98,5 \%$ & $91,6 \%$ \\
\hline É comum ver meninos e meninas menores de 18 anos se prostituindo & $93,7 \%$ & $89,6 \%$ & $79,1 \%$ \\
\hline $\begin{array}{c}\text { É comum ver crianças/adolescentes se prostituindo em postos e } \\
\text { estradas }\end{array}$ & $88,4 \%$ & $84,6 \%$ & $70,2 \%$ \\
\hline $\begin{array}{c}\text { Em geral, meus colegas caminhoneiros saem com meninas e } \\
\text { meninos menores de 18 anos para fazer programas }\end{array}$ & $85,8 \%$ & $70,0 \%$ & $47,6 \%$ \\
\hline É comum ver colegas dando carona para menores de idade & $71,7 \%$ & $51,5 \%$ & $40 \%$ \\
\hline
\end{tabular}

Fonte: CERQUEIRA-SANTOS, 2015, p. 24.

Destaca-se nos percentuais da pesquisa: a) Que é comum ver meninos e meninas em atividades de exploração sexual comercial - responderam "sim” - em 2005 - 93,7\%, em 2010 - 89,6\%, e em $2015-79,1 \%$, indicadores expressivos e que tiveram queda insignificante no decorrer dos anos; b) É comum ver crianças/adolescentes na exploração sexual comercial em postos e estradas - responderam "sim" - em 2005 - 88,4\%, em 2010 - 84,6\%, e em 2015 $70,2 \%$, indicadores significativos e que também possuíram leve baixa no passar dos anos; c) 
Em geral, meus colegas caminhoneiros realizam exploração sexual comercial com meninas e meninos - responderam "sim" - em 2005 - 85,8\%, em 2010 - 70\%, e em 2015 - 47,6\%, indicadores também significativos, mas que tiveram considerável baixa com o transcorrer dos anos, o que pode evidenciar maior conscientização em face do desenvolvimento de campanhas no lapso de dez anos (CERQUEIRA-SANTOS, 2015, p. 24).

Além disso, verificou-se a média do valor pago, a qual foi de R 17,26 em 2005 e de $\mathrm{R}$ \$ 25,05 em 2010. Observando-se, com isso, a completa exploração, visto os parcos valores auferidos por quem não dispõe de condições mínimas de subsistência (CERQUEIRASANTOS, 2010, p. 10-11).

Tabela 2: Valor pago exploração sexual comercial - exposto por caminhoneiros

\begin{tabular}{|c|c|}
\hline $\mathbf{2 0 0 5}$ & $\mathbf{2 0 1 0}$ \\
\hline $\mathrm{R} \$ 17,26$ & $\mathrm{R} \$ 25,05$ \\
\hline
\end{tabular}

Fonte: CERQUEIRA-SANTOS, 2010, p. 10-11; CERQUEIRA-SANTOS, 2015, p. 17.

Outrossim, constatou-se que as crianças e os adolescentes são incentivados a sujeitaremse à exploração sexual comercial, visto que os encargos com a sobrevivência familiar são impostos a elas, possuindo os membros das famílias conhecimentos dos fatos e, inclusive, sendo determinantes para que eles ocorram. A situação de privação ou negação econômica e de direitos é elemento motivador para o desenvolvimento familiar, ocorrendo a obrigação precoce de incumbências que pertencem aos adultos (DILACIO; GIORGI; VARELA, 2012, p. 189; 193).

No ponto de vista dos caminhoneiros, a necessidade financeira e a exploração adulta foram consideradas as principais causas da exploração sexual comercial:

\begin{tabular}{|c|c|c|c|}
\hline $\begin{array}{r}\text { Principal Motivo } \\
\end{array}$ & 2015 & 2010 & 2005 \\
\hline Por necessidade financeira da criança ou da família. & $72,8 \%$ & $79,4 \%$ & $39 \%$ \\
\hline Porque são explorados/ obrigados por alguém & $20,3 \%$ & $34,1 \%$ & $16 \%$ \\
\hline Porque há mercado fácil para elas(es) & $11,1 \%$ & $23,7 \%$ & $4 \%$ \\
\hline Porque elas(es) gostam de sexo (têm prazer). & $11,9 \%$ & $19,5 \%$ & $14 \%$ \\
\hline Porque é o que há disponível para fazer & $9,2 \%$ & $12 \%$ & $10 \%$ \\
\hline Porque existem adultos que gostam, que procuram & $6,9 \%$ & $13,5 \%$ & $2 \%$ \\
\hline
\end{tabular}

Fonte: CERQUEIRA-SANTOS, 2015, p. 26. 
Existem regiões onde a exploração sexual comercial ocorre nos portos fluviais, que são pontos de comercialização de serviços, mercadorias e transporte de passageiros, constatandose a globalização econômica como uma causa. Embora seja um local com vasta movimentação econômica, os portos fluviais possuem situações de pobreza no seu entorno, favorecendo a desigualdade social e a exploração sexual comercial de crianças e adolescentes. Nessas localidades, os principais exploradores sexuais comerciais são os portuários e as principais vítimas são as crianças e adolescentes em condição de pobreza ou extrema pobreza (MUJICA; CAVAGNOUD, 2011, p. 97-101).

As crianças e adolescentes que vivem em situação de rua são violentadas, discriminadas e exploradas frequentemente, e, em regra, consideradas “invisíveis". Essa situação de rua é causadora da negação de direitos em virtude da exclusão social, o que, frequentemente, conduz à exploração sexual comercial de crianças e adolescentes ou demais formas de trabalho infantil (COMISIÓN ESTATAL DE DERECHOS HUMANOS DE JALISCO - CEDHJ, 2017, p. 1-2; $72 ; 86)$.

A extrema pobreza é elemento que impulsiona à exploração sexual comercial, que, por sua vez, ocasiona a evasão escolar. Verificou-se, numa pesquisa feita no município de Santa Marta na Colômbia, na qual foram entrevistadas 52 meninas vítimas da exploração sexual comercial, com idade entre dez e dezoito anos, que 76,9\% delas abandonaram o sistema escolar no sétimo, oitavo ou nono ano (AMAR et al., 2006, p. 176-177).

O analfabetismo, a evasão escolar e a falta de acesso à educação são elementos decisivos para a exclusão econômica e social. Ressalta-se, negativamente, que a população mais pobre possui menores taxas de alfabetização em comparação a mais rica. Essa também é uma regra, com um distanciamento mais significativo entre a população mais pobre e mais rica, no caso da evasão escolar de adolescentes do ensino médio. Esta ocorre justamente no período onde se começa a laborar, prejudicando-se os estudos e afastando oportunidades futuras. No tocante às taxas de frequência escolar no ensino fundamental, assemelham-se as classes mais pobres com as mais ricas. Já sobre os acessos a pré-escola e a creche, os distanciamentos também são muito significativos (TODOS PELA EDUCAÇÃO, 2014). 


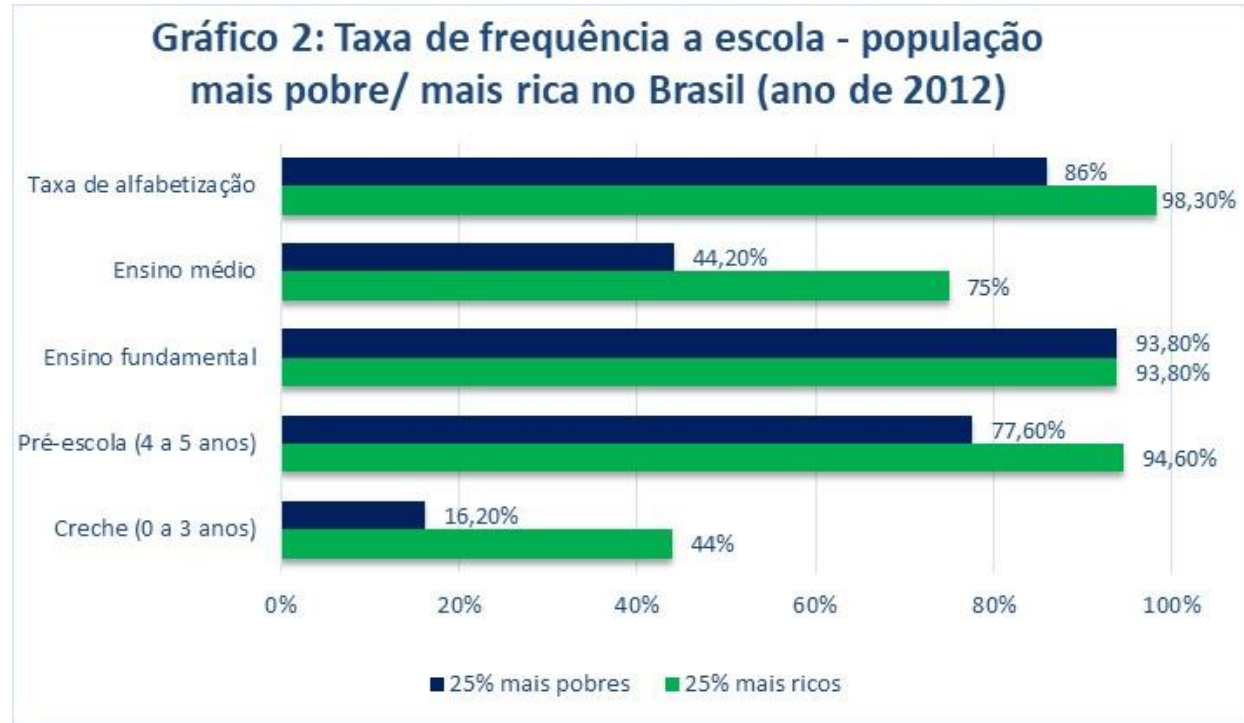

FONTE: Todos pela educação/IBGE/PNAD.

A garantia da condição de cidadania plena depende do acesso e continuidade do direito à educação, preferencialmente, no período da infância. Para tanto, é necessário combater os motivos que levam a evasão escolar de crianças e adolescentes (CUSTÓDIO; MOREIRA, 2019, p. 298). O impacto ocasionado pelo abandono escolar frustra as melhores chances para o futuro, gerando a perpetuação dos ciclos de pobreza ou extrema pobreza e impedindo a inclusão social (MOREIRA; CUSTÓDIO, 2015, p. 239).

Além disso, a evasão escolar gerada pela exploração do trabalho infantil influencia na remuneração percebida no decorrer da vida adulta, visto que, quanto mais cedo for a entrada no mercado de trabalho, mais baixa será a renda auferida. Tudo isso, em face do grau de instrução e profissionalização, os quais, consequentemente, serão menores, permanecendo-se as situações de pobreza e as elevadas taxas de desigualdade social (BRASIL, 2011, p. 21).

Nota-se que a renda média é proporcional ao grau de instrução no Brasil, visto que, quanto mais baixo o nível de escolaridade, menor será o rendimento auferido. 


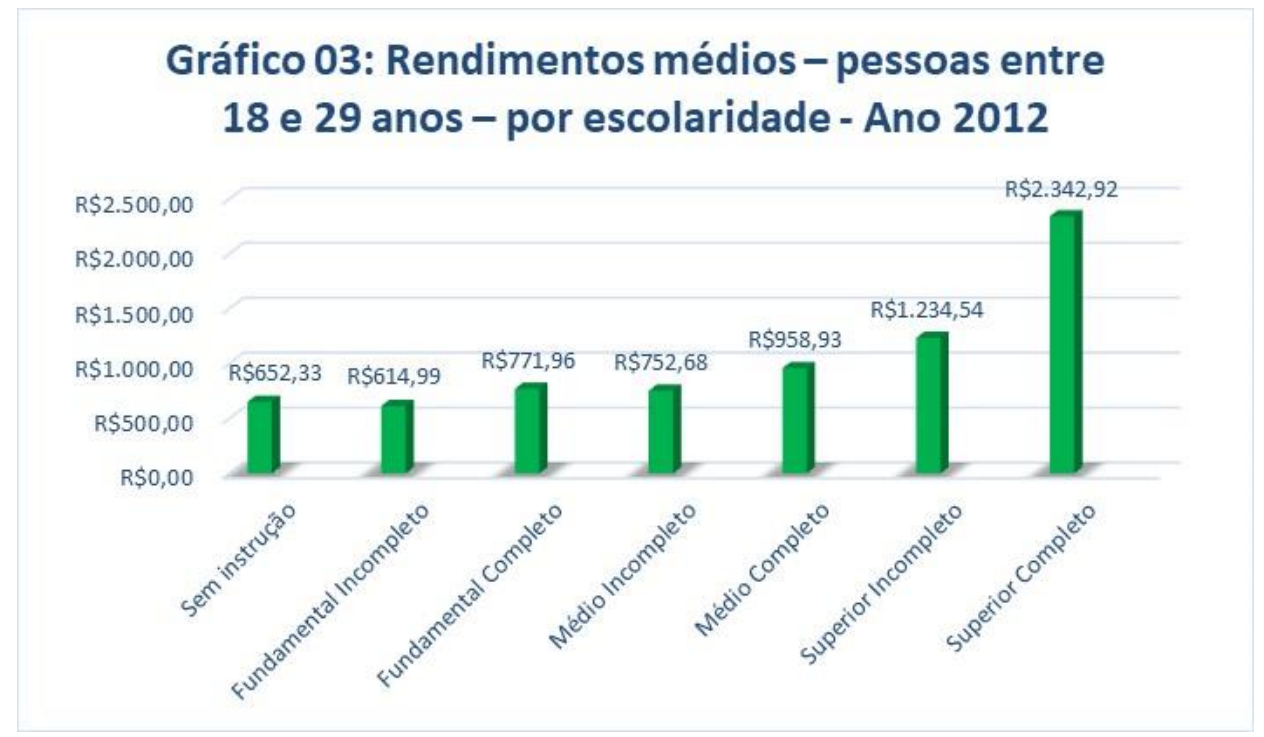

Fonte: Todos pela educação/IBGE/PNAD

Em virtude das piores oportunidades futuras que decorrem da evasão escolar pela exploração sexual comercial, tem-se a perpetuação dos ciclos intergeracionais da pobreza como causa e consequência para o problema (CUSTÓDIO; MOREIRA, 2015, p. 87-95).

Foram analisadas, em regiões fronteiriças do Brasil com o Uruguai, mais precisamente nos municípios de Río Branco, Rivera, Bella Unión e Chuy, os perfis geracionais e de gênero das vítimas e dos agressores da exploração sexual comercial. O perfil característico da vítima foi o de adolescente do gênero feminino, enquanto o explorador era adulto do sexo masculino. Nessas regiões, registra-se uma convicção de senso comum de culpabilização da vítima pela exploração sexual comercial, principalmente pelo fato da distinção de poder pelo gênero e geração (DILACIO; GIORGI; VARELA, 2012, p. 187-188).

A ideologia patriarcal e classista sustenta a exploração sexual comercial, restringindo as pessoas à situação de submissão e violação de direitos em face de seu gênero, raça/etnia e classe social. Tendo em vista os mecanismos que objetivam resguardar posições favorecidas no mercado de trabalho e na sociedade a uma parte dos brasileiros, a exclusão social e econômica é mais considerável para algumas categorias. Observa-se que, em vista das representações ideológicas opressoras em prol de elites e do mercado, há classes sociais que têm maior potencialidade de ser discriminada, explorada e violentada (LEAL; LEAL, 2002, p. 52; 54-57; $68 ; 140 ; 222)$. 
Outras causas importantes para ocorrer a exploração sexual comercial é a coisificação da infância, a qual ocorre em virtude da mercantilização de pessoas e do tratamento de crianças e adolescentes como objetos, equiparando-se a "coisas" que pertencem aos adultos e ficam em segundo plano nas relações sociais (CUSTÓDIO; MOREIRA, 2015, p. 80-85). E o adultocentrismo, que consiste na "inferiorização" atribuída a crianças e adolescentes, como se possuíssem menos direitos e garantias, cabendo ao adulto ser o centro das relações sociais (VERONESE, 2015a, p. 32-33).

Salienta-se as principais causas que conduzem os adultos a desejar relações sexuais com crianças e adolescentes no cenário das rodovias federais brasileiras, indicando práticas de adultocentrismo que coisificam a infância:

\begin{tabular}{|c|c|c|c|}
\hline \multicolumn{4}{|c|}{ Tabela 4: Motivações para buscar a exploração sexual comercial } \\
\hline Motivação & $\mathbf{2 0 1 5}$ & $\mathbf{2 0 1 0}$ & $\mathbf{2 0 0 5}$ \\
\hline Por ter mais excitação e prazer & $45,6 \%$ & $46,7 \%$ & $36,3 \%$ \\
\hline Por "safadeza e falta de vergonha na cara" & $35,8 \%$ & $53,6 \%$ & $21,5 \%$ \\
\hline Para satisfazer as necessidades do momento & $14,1 \%$ & $21,8 \%$ & $19 \%$ \\
\hline Para se sentir poderoso & $7,6 \%$ & $18,8 \%$ & $15,7 \%$ \\
\hline $\begin{array}{c}\text { Para aumentar a autoestima frente a alguém incapaz de questionar o seu } \\
\text { desempenho }\end{array}$ & $7,2 \%$ & $19,5 \%$ & $7,4 \%$ \\
\hline
\end{tabular}

Fonte: CERQUEIRA-SANTOS, 2015, p. 26.

Em pesquisa realizada com vítimas, identificou-se dados que apontam causas ou indicativos para a ocorrência da exploração sexual comercial de crianças e adolescentes. Verificou-se que em $88,2 \%$ dos casos, as vítimas moram com a família, havendo estímulo familiar ou naturalização dessa condição; em 44\%, se submeteram à exploração em busca de dinheiro para comprar drogas, com o intuito da satisfação da dependência química ou da busca por um refúgio; em $44,4 \%$ dos casos não receberam o pagamento em dinheiro, ficando evidente a situação de negação de direitos e exploração que se encontram; quanto a alfabetização dos genitores: $36,1 \%$ dos pais e $50 \%$ das mães possuem o ensino fundamental, e 16,4\% dos pais e 19,7\% das mães são analfabetos; $30 \%$ dos entrevistados não estavam estudando, o que indica a condição de exclusão social. Com isso, constata-se que a baixa escolaridade familiar, como questão de desigualdade ou exclusão social, interferem na exploração sexual comercial. Além disso, verificou-se que o valor médio auferido com as atividades foi de $\mathrm{R} \$ 37,00$ (trinta e sete reais) (CERQUEIRA-SANTOS, [s.d.], p. 06-13). 


\section{Tabela 5: Características da exploração sexual comercial}

\begin{tabular}{|c|c|}
\hline Fator & Indicador \\
\hline Valor médio recebido pelas vítimas & $\mathrm{R} \$ 37,00$ \\
\hline Vítimas que vivem com a família & $88,2 \%$ \\
\hline Vítimas que não receberam remuneração em dinheiro & $44,4 \%$ \\
\hline Vítimas que realizaram atividades de cunho sexual em troca de dinheiro para aquisição de \\
drogas & $44 \%$ \\
\hline Vítimas que não estavam estudando na data da realização da pesquisa & $30 \%$ \\
\hline Mães das vítimas - escolaridade de ensino fundamental & $50 \%$ \\
\hline Pais das vítimas - escolaridade de ensino fundamental & $36,1 \%$ \\
\hline Mães das vítimas - analfabetas & $19,7 \%$ \\
\hline Pais das vítimas - analfabetos & $16,4 \%$ \\
\hline
\end{tabular}

Fonte: CERQUEIRA-SANTOS, [s.d.].

Em pesquisa com crianças e adolescentes, na maior parte sendo do sexo feminino, analisou-se as consequências sofridas pelas vítimas de exploração sexual comercial, as quais relataram que: pensaram em suicídio - $60,9 \%$; tentaram o suicídio - $58,1 \%$; expuseram como principal motivação para os pensamentos ou as tentativas de suicídio: vício em drogas $-15,7 \%$; exploração sexual comercial - 20\%; ficaram grávidas pelo menos uma vez - 30\%; já tiveram abortos naturais ou provocados - 30\%; vivem com seus filhos, indicando o rompimento da ligações familiares e necessidade de acolhimento dos filhos - 5,8\%; afirmaram ser HIV positivo - 8\%; quanto aos métodos contraceptivos: utilizaram sempre algum método - 44\%; utilizaram as vezes - 34\%; e nunca utilizaram - 22\%; a média de idade em que as vítimas tiveram seu primeiro filho, foi entre 13 e 14 anos, sendo que 21,7\% delas foram expulsas de casa pela família e um terço delas precisou abandonar a escola (CERQUEIRA-SANTOS, [s.d.], p. 8-11).

\begin{tabular}{|c|c|}
\hline \multicolumn{2}{|c|}{ Tabela 6: Consequências da exploração sexual comercial } \\
\hline Fator & Indicador \\
\hline Pensaram em suicídio & $60,9 \%$ das vítimas \\
\hline Tentaram o suicídio & $58,1 \%$ das vítimas \\
\hline $\begin{array}{c}\text { Expuseram a exploração sexual comercial como principal motivação para a tentativa } \\
\text { ou o pensamento em suicídio }\end{array}$ & $20 \%$ das vítimas \\
\hline $\begin{array}{c}\text { Indicaram o vício em drogas como principal motivação para a tentativa ou o } \\
\text { pensamento em suicídio }\end{array}$ & $15,7 \%$ das vítimas \\
\hline Já ficaram grávidas ao menos 1 (uma) vez & $30 \%$ das vítimas \\
\hline Já perderam filhos em abortos naturais ou forçados & $17 \%$ das vítimas \\
\hline Vivem com seus filhos atualmente & $5,8 \%$ das vítimas \\
\hline São HIV positivo & $8 \%$ das vítimas \\
\hline Utilizam sempre algum método contraceptivo & $44 \%$ das vítimas \\
\hline Nunca utilizam métodos contraceptivos & $34 \%$ das vítimas \\
\hline Média de idade em que teve o primeiro filho & $22 \%$ das vítimas \\
\hline Abandonaram a escola em decorrência da gravidez & 13 e 14 anos \\
\hline Foram expulsas de casa pela família & $1 / 3$ das vítimas \\
\hline
\end{tabular}

Fonte: CERQUEIRA-SANTOS, [s.d.], p. 08-11. 
Em pesquisa realizada em Bogotá na Colômbia, revelou-se a combinação da utilização de substâncias psicoativas com a exploração sexual comercial de crianças e adolescentes. Constatou-se que, no tocante a 225 crianças e adolescentes vítimas dessa exploração, 89,8\% fizeram o uso de alguma substância psicoativa (PINZÓN-RONDON; et al., 2009, p. 472).

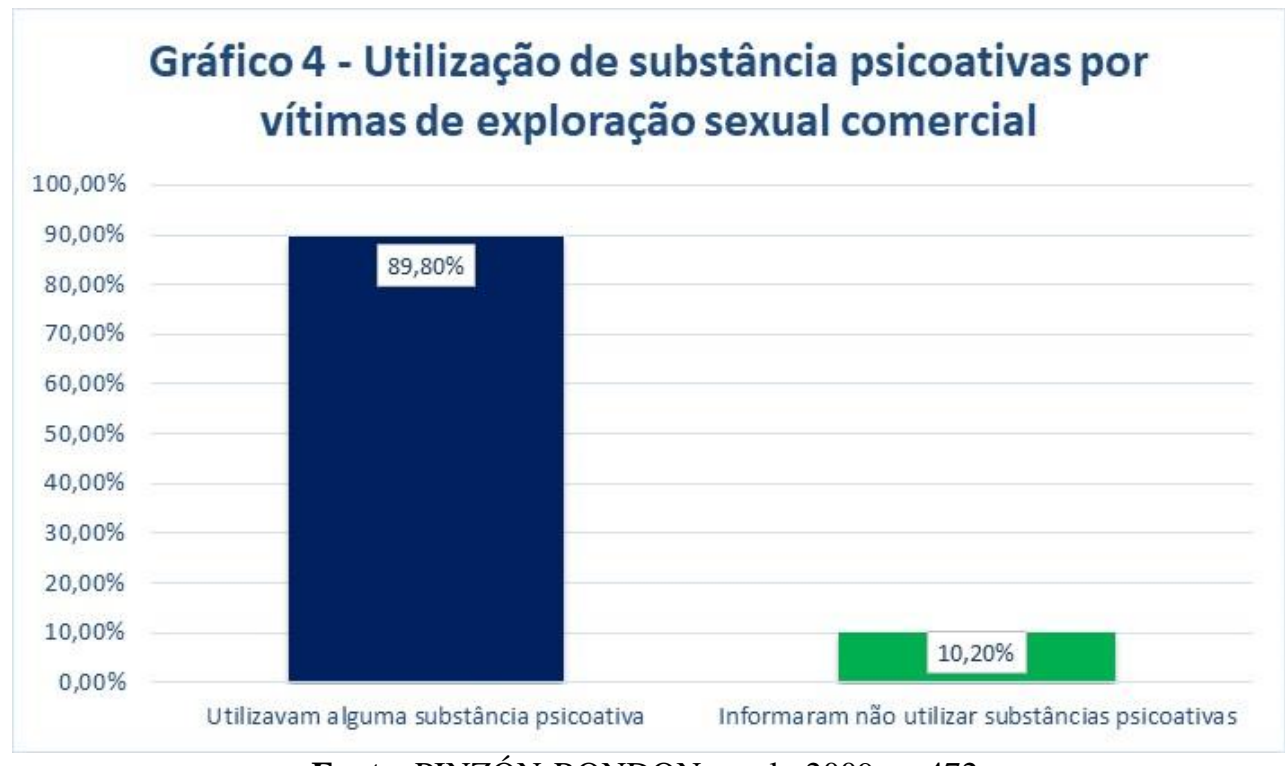

Fonte: PINZÓN-RONDON; et al., 2009, p. 472.

Em pesquisa realizada nos municípios fronteiriços da Tríplice Fronteira entre Brasil, Argentina e Paraguai, extraiu-se que a exploração sexual comercial acontecia em boates, ruas, motéis ou bares. Observou-se que as vítimas são tanto do sexo feminino como do masculino, com idades a partir dos 10 anos, e que além de auferirem ínfimas quantias, frequentemente as dividiam com seus aliciadores, o que restava era voltado para a subsistência familiar e individual. Verificou-se, ainda, que algumas das vítimas vivem em situação de rua, em face da violência que era recebida em suas residências (MORAES, 2009, p. 54-60; 94-111).

Já nas regiões da floresta amazônica, as características arguidas pelas vítimas dessa exploração transmitem a ideia de naturalização das atividades, as quais são forçadas ou estimuladas nas suas próprias residências. As vítimas sofrem inúmeras privações essenciais ao desenvolvimento humano, principalmente as de condições econômicas, sendo que, em muitas das vezes, ocorre a violação de direitos pelo abuso sexual no âmbito intrafamiliar. Observa-se que a subordinação à exploração sexual comercial sucede das necessidades financeiras em regiões onde existe comércio de garimpo, movimentações portuárias, trânsitos fronteiriços de 
pessoas em cidades distintas da região e transporte fluvial. Esse comércio sexual é buscado por adultos com uma visão de subordinação e violência de gênero, efetuando-se, inclusive, por autoridades públicas, como políticos e policiais, num cenário de pouca informação e difícil enfrentamento (CONTRERAS, 2015, p. 114-150).

Importa salientar, que na maioria absoluta dos casos, a exploração sexual comercial de crianças e adolescentes efetuou-se em virtude das condições de pobreza que conduzem à procura por dinheiro, e em várias explanações, teve como precedente uma ocorrência de violência sexual intrafamiliar, retratando-se um encadeamento de coisificação da infância e de restrição de oportunidades de escolhas (LOPES, 2009, p. 128-132).

A constatação das características de cada localidade, a fim de que se observe os diversos problemas em suas singularidades, é essencial para o combate à exploração sexual comercial de crianças e adolescentes. Pois, existem particularidades distintas em cada ambiente, necessitando de devida atenção para as atividades exploratórias que acontecem nas mais distintas regiões. Portanto, o conhecimento das características locais e das peculiaridades da exploração é de suma importância, visto que há variações relevantes na situação de cada município, sendo necessário que esse elemento seja analisado como único diante da estruturação da elaboração do planejamento da prevenção e erradicação da exploração sexual comercial de crianças e adolescentes.

\section{O ENFRENTAMENTO DA EXPLORAÇÃO SEXUAL COMERCIAL DE CRIANÇAS E ADOLESCENTES NOS MUNICÍPIOS: O CICLO DE ETAPAS DE POLÍTICAS PÚBLICAS NO SISTEMA DE GARANTIA DE DIREITOS E NA REDE DE ATENDIMENTO}

Em termos conceituais, as políticas públicas são um conjunto de ações desenvolvidas para resolver um problema social de ordem política que foi identificado pela agenda governamental e necessita de uma resposta (SUBIRATS; et al. 2008, p. 35; 38).

Política pública pode ser definida como um conjunto de decisões e ações desencadeadas por órgãos públicos e entes da sociedade, dotadas de coerência 
intencional, que, sob coordenação estatal, visam a enfrentar um problema político. Toda política pública é uma tentativa de intervenção na realidade social, seja de controle ou de mudança. A política é deflagrada com base na percepção de que uma situação indesejada requer intervenção dos poderes públicos. Origina-se, assim, um problema político (SCHIMDT, 2016, p. 1-2).

As políticas públicas podem ser definidas como um programa de ações governamentais que são decorrentes de processos regulados de maneira jurídica com o intuito de executar demandas públicas de importância social e que foram decididas politicamente (BUCCI, 2013, p. 37-38).

As políticas públicas são compostas por distintas fases, caracterizando-se pela constante movimentação. Os ciclos possuem etapas definidas de maneira geral: "Fase 1: Percepção e definição de problemas"; "Fase 2: Inserção na agenda política"; "Fase 3: Formulação"; "Fase 4: Implementação"; "Fase 5: Avaliação" (SCHMIDT, 2008, p. 2316-2320).

As fases dos ciclos de políticas públicas são propostas de maneira diferente pelos autores. A demonstração de que as políticas públicas possuem as etapas a serem percorridas num ciclo é defendida por vários pesquisadores, havendo caminhos que são próprios no pensamento de cada um.

Posteriormente ao momento da criação da política pública, há o direcionamento para sua implementação por meio de planejamento e execução, seguindo a lógica de confecção de: "[...] planos, programas, projetos, bases de dados ou sistema de informação e pesquisas. Quando postas em ação, são implementadas, ficando daí submetidas a sistemas de acompanhamento e avaliação" (SOUZA, 2006, p. 26).

É importante que não ocorra a descontinuidade da política pública em decorrência de abandono de diretrizes ou mudança de prioridades, o que prejudicaria o processo cíclico, impactaria negativamente na sociedade e traria como consequência o: “[...] desperdício de energia política e de recursos financeiros" (SCHMIDT, 2008, p. 2312).

A realização do ciclo de etapas de políticas públicas é fundamental para o efetivo enfrentamento da exploração sexual comercial de crianças e adolescentes no ente federado mais perto da comunidade. Os municípios possuem papel relevante no desenvolvimento sistêmico das políticas públicas, necessitando ter mecanismos que proporcionem o conhecimento da legislação sobre o assunto e a identificação das peculiaridades que devem ser focadas na esfera 
local, utilizando as características gerais sobre o problema e os dados contextuais como base inicial para o planejamento de ações e estratégias.

As políticas públicas têm por objetivo assegurar os direitos protegidos juridicamente pelo Estado brasileiro. Para o seu desenvolvimento é necessário o cumprimento de etapas que visam otimizar a sua execução, por meio de um ciclo de atividades previamente estabelecido, planejado e controlado por uma equipe gestora. As políticas públicas com atribuições na prevenção e erradicação da exploração sexual comercial de crianças e adolescentes seguem essa lógica, contando com a participação de distintas instituições e equipes técnicas que devem agir de maneira alinhada, a partir de um planejamento prévio que expresse as estratégias e ações focalizadas por objetivo comum.

A execução de ações estratégicas de prevenção e erradicação da exploração sexual comercial de crianças e adolescentes ocorre no âmbito municipal e necessita ser antecedida por um planejamento que esteja de acordo com as características locais, isso se dá em face das suas complexidades e distinções causais nos diferentes espaços. O contexto local é único, o que remete para que haja a observância da necessidade de variações de ações e estratégias no planejamento e execução das políticas públicas. Neste processo de construção de planejamento, destaca-se a importância dos diagnósticos prévios com o objetivo de entender o contexto do município, proporcionando que haja a estruturação correta da política pública e se siga um percurso cíclico (MOREIRA, 2020, p. 153; 203; 232).

Os diagnósticos são instrumentos fundamentais para a otimização das políticas públicas e devem ser realizados de forma periódica, ocorrendo mediante a coleta de dados e informações no Sistema de Garantia de Direitos da Criança e do Adolescente, na Rede de Atendimento e nos ambientes sociais. Com a coleta e a interpretação dos materiais, pode-se realizar a caracterização do problema, o planejamento focalizado da execução e as oportunidades de melhoria das ações, estratégias, diretrizes e metas das políticas públicas (VERONESE; LEME, 2017, p. 251).

[...] pode-se constatar que o conhecimento sobre o fenômeno é o primeiro passo para quem se propõe a enfrentá-lo, não um conhecimento raso, mas um aprofundamento do mesmo. Aliado a isso, há a necessidade de compreender os mecanismos que dão possibilidade de intervenção efetiva, para isso é preciso analisar o fenômeno em seu contexto, mas ligando-o as questões mais amplas. Os mecanismos para o enfrentamento estão hoje previstos nas políticas públicas, porém, o que utilizar e como utilizar irá depender da demanda particularizada (CORGOZINHO, 2009, p. 114). 
Os diagnósticos devem servir de base para as deliberações dos Conselhos Municipais dos Direitos da Criança e do Adolescente, necessitando ser realizados periodicamente mediante a coleta de dados em instituições intersetoriais na esfera municipal (SOUZA; CUSTÓDIO, 2018, p. 182-183).

O planejamento das ações e estratégias municipais de enfrentamento da exploração sexual comercial deve ser realizado atentando para as características identificadas no diagnóstico, mapeadas nos estudos e retratadas nos indicadores intersetoriais, observando as diretrizes nacionais e estaduais.

O Brasil não possui um plano específico de enfrentamento da exploração sexual comercial de crianças e adolescentes, entretanto, por ser um tema que simultaneamente é uma modalidade de trabalho infantil e um tipo de violência sexual, deve estar alinhado as previsões do Plano Nacional de Prevenção e Erradicação do Trabalho Infantil e Proteção do Adolescente Trabalhador e do Plano Nacional de Enfrentamento da Violência Sexual Contra Crianças e Adolescentes. Porém, tais instrumentos são gerais e não observam muitas das especificidades da exploração sexual comercial de crianças e adolescentes, tornando-se subsidiário quando da existência de planos temáticos específicos nos entes federados (MOREIRA, 2020, p. 154; 162; 232).

Os Conselhos Municipais dos Direitos da Criança e do Adolescente são os órgãos de gestão local vinculados ao Poder Executivo e possuem atribuições de deliberação sobre políticas públicas, sendo o principal responsável pelo seu planejamento, controle e monitoramento. O poder local é o espaço para a realização das políticas públicas, mediante prévio planejamento que deverá utilizar dos instrumentos de democracia participativa com o exercício ativo dos cidadãos (SOUZA; CUSTÓDIO, 2018, p. 179-181).

Pode-se verificar, com a análise empírica, que existem Conselhos Municipais dos Direitos da Criança e do Adolescente que não estão conseguindo planejar o enfrentamento das violações de direitos da criança e do adolescente, dentre elas a exploração sexual comercial, por falta de capacitação e formação continuada (LIMA; MOREIRA, 2020, p. 318-320).

Defende-se a necessidade de planos específicos para o enfrentamento da exploração sexual comercial de crianças e adolescentes em decorrência da meta firmada pelo Brasil, junto 
à ONU, em erradicar tal violação de direitos até o ano de 2025, bem como por possuir maiores especificidades temáticas em relação à violência sexual e ao trabalho infantil. Portanto, é fundamental a confecção do Plano Municipal de Prevenção e Erradicação da Exploração Sexual Comercial de Crianças e Adolescentes para o enfrentamento do problema contemplando as peculiaridades da esfera local. Para tanto, é necessário a formação de equipe gestora, com coordenação própria e autônoma, que atuará no formato de um programa, delimitará responsabilidades e traçará metas, diretrizes, eixos, roteiros, fluxos, protocolos, estratégias, ações e calendário de atividades anuais (MOREIRA, 2020, p. 212; 233-235).

Salienta-se que as ações estratégicas apresentadas nos planos municipais necessitam observar os estudos sobre o tema e importar práticas exitosas para coibir o problema que estão sendo ou foram realizadas pelo Estado e pela sociedade civil em outras localidades.

Os fluxos são mecanismos basilares para a organização do planejamento da prevenção e erradicação da exploração sexual comercial de crianças e adolescentes nos municípios brasileiros, sendo variáveis de acordo com cada universo de abrangência. Eles funcionam como protocolos de procedimentos dos órgãos do Sistema de Garantia de Direitos e da Rede de Atendimento no que diz respeito à identificação, notificação, encaminhamento e responsabilização de casos de exploração sexual comercial (MOREIRA, 2020, p. 236; 253).

No Brasil já houve a instituição de políticas públicas voltadas para crianças e adolescentes que possuem atribuições no enfrentamento da exploração sexual comercial. Entretanto, elas vêm ocorrendo sem atentar para o percurso cíclico correto e que proporcione os resultados esperados. A execução das ações estratégicas de prevenção e erradicação da exploração sexual comercial deve ocorrer de forma articulada, intersetorial, em rede, descentralizada no âmbito do Sistema de Garantia de Direitos de Crianças e Adolescentes, em três níveis políticos de atuação, e da Rede de Atendimento.

O Sistema de Garantia de Direitos de Crianças e Adolescentes atua no nível de atendimento, proteção e justiça. O $1^{\circ}$ nível é o de atendimento, que é aquele que irá disponibilizar os serviços que garantam os direitos à educação, saúde, assistência social, cultura, esporte, lazer e segurança pública. O planejamento da execução das políticas públicas da Rede de Atendimento é realizado pelos Conselhos dos Direitos da Criança e do Adolescente, incluindo-se a indicação das atribuições das equipes técnicas de tais órgãos na prevenção e 
erradicação da exploração sexual comercial. O $2^{\circ}$ nível é o de proteção, que é aquele que irá ser o responsável por enfrentar a ameaça ou violação de direitos de crianças e adolescentes, por meio da atuação dos agentes públicos dos Conselhos Tutelares, Ministério Público dos estados, Ministério Público Federal, Ministério Público do Trabalho e Ministério do Trabalho em suas competências. As políticas públicas que atuam na proteção devem, imediatamente ao recebimento de comunicação, agir para modificar todas as práticas que ameacem ou violem direitos de crianças e adolescentes, nelas abrangidas a exploração sexual comercial. E o $3^{\circ}$ nível é o de justiça, que é exercido pelo Sistema de Justiça e visa realizar a responsabilização pelas violações de direitos de crianças e adolescentes, bem como garantir e defender os seus direitos na perspectiva individual, coletiva ou difusa. É exercido pela atuação do Ministério Público, Defensoria Pública e do Poder Judiciário (CUSTÓDIO; MOREIRA, 2018, p. 308-309).

As políticas públicas que atuam no enfrentamento da exploração sexual comercial de crianças e adolescentes possuem atribuições, também, de ação no processo de sensibilização da sociedade mediante a divulgação de informações sobre o tema e a promoção de direitos da criança e do adolescente. As atividades devem ser habituais e cíclicas em locais estratégicos da comunidade, o que visa modificar as práticas culturais permissivas, multiplicar a reprodução de informações sobre o assunto, empoderar cidadãos e demonstrar os canais para a realização da comunicação dos fatos (MOREIRA; CUSTÓDIO, 2019, p. 138-140).

Neste sentido, faz-se essencial o investimento em capacitação e formação continuada de equipes técnicas que atuem nas políticas públicas destinadas à crianças e adolescentes, proporcionando a habilidade de recebimento de comunicação de fatos de violação de direitos, sensibilização sobre o tema, identificação de casos na sua esfera de atuação, notificação da informação nas bases de dados oficiais e realização dos encaminhamentos necessários, estabelecendo-se efetivos canais de enfrentamento ao problema (MOREIRA; CUSTÓDIO, 2019, p. 140-141).

As capacitações devem ser periódicas, em vista da modificação das equipes técnicas, e universais, com a preparação de todos que atuam na prevenção e erradicação da exploração sexual comercial de crianças e adolescentes. Nas capacitações devem ser reforçados o papel da rede intersetorial e articulada, assim como a relevância da comunicação e colaboração recíproca entre equipes e órgãos (MOREIRA, 2020, p. 236-237). 
O monitoramento por meio de diagnósticos das políticas públicas conta com a análise dos indicadores, o que proporciona informações sobre questões sociais em todos os entes federados. Os indicadores são ferramentas essenciais para a tomada de decisões e monitoramento, sendo que sua coleta deve ser aprimorada de forma constante (SILVA; SOUZA-LIMA, 2010, p. 37).

Os indicadores proporcionam o monitoramento do desempenho das políticas públicas e dos comportamentos sociais, sendo mecanismos de avaliação do cumprimento dos objetivos estabelecidos e aperfeiçoamento de ações estratégicas, o que possibilita a manutenção ou a proposição de reordenamento em termos de planejamento e execução das políticas públicas. São os indicadores que demonstrarão os resultados das políticas públicas, tornando-se essenciais, por meio da coleta de dados quantitativos e/ou qualitativos que são pré-estabelecidos de acordo com critérios técnicos, para a demonstração de êxito ou necessidade de melhorias (SILVA; SOUZA-LIMA, 2010, p. 47-48; 57-59).

Os bancos de dados públicos de indicadores atrelados ao exercício de políticas públicas devem ser alimentados com registros continuamente. A rotina das equipes técnicas que atendem crianças e adolescentes necessita contemplar a necessidade compulsória de notificação de toda e qualquer violação de direitos identificada ou comunicada no seu universo de atividades, para que se possa entender o fenômeno com precisão, retratar a realidade local, evitar a subnotificação de casos e agir para a modificação da situação (MOREIRA, 2020, p. 238-239).

O monitoramento das políticas públicas destinadas à infância proporciona ao gestor a identificação dos impactos relacionados ao planejamento inicial, identificando-se avanços e/ou retrocessos, assim como oportunizando o reordenamento dos rumos estratégicos e a revisão das ações com a periodicidade necessária (BRASIL, 2019, p. 46).

Diante do percurso realizado em relação ao papel das políticas públicas na prevenção e erradicação da exploração sexual comercial de crianças e adolescentes nos municípios, propõese um ciclo de atividades que orientam a gestão e disponibilizam um acompanhamento continuado. 


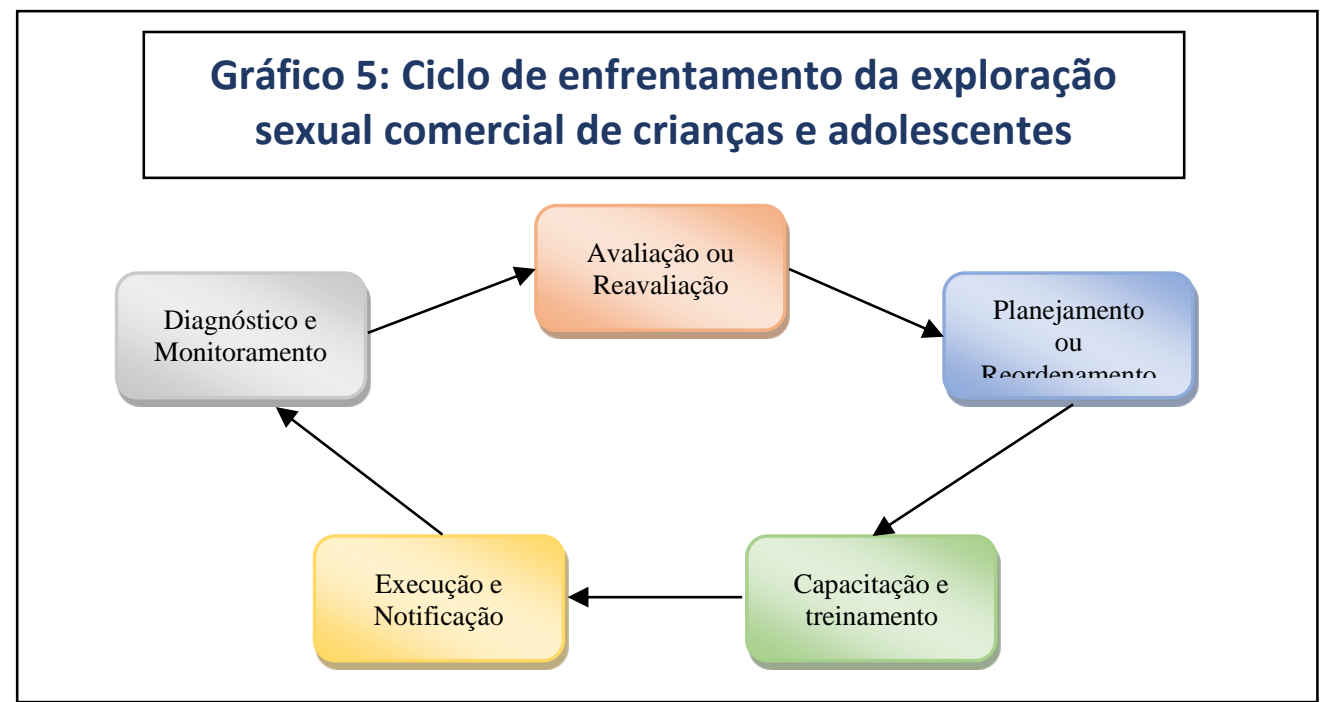

Portanto, o enfrentamento da exploração sexual comercial de crianças e adolescentes segue um percurso cíclico em constante movimentação. No ciclo apresentando, o primeiro passo é o diagnóstico para o conhecimento da realidade local, seguindo-se pela avaliação do cenário e o planejamento focalizado do enfrentamento. Antes da realização das atividades, fazse necessário a capacitação e o treinamento das equipes técnicas para a posterior execução efetiva das atividades, primando-se para a notificação de todos os casos identificados. Como a proposição é de um ciclo, reinicia-se com novos diagnósticos e o monitoramento da realização das atividades, passando por uma reavaliação que indique avanços, dificuldades e oportunidades de melhoria, o que pode indicar um reordenamento no planejamento. Novas capacitações para garantir a formação continuada e treinamentos são necessários, visando constante otimização da execução e notificação, que são contínuas.

\section{CONCLUSÕES}

A proteção jurídica para o combate da exploração sexual comercial de crianças e adolescentes está consolidada no Brasil e cumpre com os compromissos internacionais ratificados, restando, como principal desafio, a execução de políticas públicas para o seu cumprimento na esfera municipal, atentando-se para as especificidades de cada localidade. 
A identificação das características de cada espaço local é fundamental para o êxito das políticas públicas e cumprimento da legislação nacional. Os espaços possuem peculiaridades distintas, reforçando-se a necessidade de diagnósticos que orientem o planejamento local.

As políticas públicas visam assegurar direitos protegidos juridicamente pelo Estado brasileiro. Para o seu desenvolvimento é necessário o cumprimento de etapas que visam otimizar a sua execução, por meio de um ciclo de atividades previamente estabelecido, planejado e controlado por uma equipe gestora.

Por último, defende-se que a prevenção e a erradicação da exploração sexual comercial de crianças e adolescentes ocorre por meio de políticas públicas intersetoriais que estão em constante movimentação num percurso cíclico. O respeito ao traçado do ciclo nos municípios aumenta a possibilidade de êxito das ações e estratégias, devido a sua focalização nas características locais e da sua continuidade.

\section{REFERÊNCIAS BIBLIOGRÁFICAS}

AMAR, José; et al. Explotación Sexual Comercial Infantil en el Distrito Turístico y Portuario de Santa Marta. Terapia Psicológica, Santiago - Chile, v. 24, n. 2, p. 175-182, dec. 2006.

BAPTISTA, Rachel Fontes; ZAMORA, Maria Helena Rodrigues Navas. Família acolhedora e reordenamento institucional: (Im)possibilidades diante do Menorismo. Revista Juris Poiesis, Rio de Janeiro, V. 22, n. 30, p. 01-22, 2019.

BRASIL. Constituição da República Federativa do Brasil. 1988. Disponível em: http://www.planalto.gov.br/ccivil_03/constituicao/constitui\%C3\%A7ao.htm. Acesso em: 06 abr. 2020.

BRASIL. Estatuto da Criança e do Adolescente. 1990. Disponível em: http://www.planalto.gov.br/ccivil_03/leis/18069compilado.htm. Acesso em: 06 abr. 2020.

BRASIL. Consolidação das Leis do Trabalho. 1943. Disponível em: http://www.planalto.gov.br/ccivil_03/Decreto-Lei/Del5452.htm. Acesso em: 10 abr. 2020. 
BRASIL. Decreto n. $\quad$ 6.481. 2008. Disponível em: http://www.planalto.gov.br/ccivil_03/_ato2007-2010/2008/decreto/d6481.htm. Acesso em: 16 jan. 2020.

BRASIL. Código Penal. 1940. Disponível em: http://www.planalto.gov.br/ccivil_03/decretolei/Del2848compilado.htm. Acesso em: 10 jan. 2020.

BRASIL. Plano Nacional de Prevenção e Erradicação do Trabalho Infantil e Proteção do Adolescente Trabalhador. Comissão Nacional de Erradicação do Trabalho Infantil. 2. ed. Brasília: Ministério do Trabalho e Emprego, 2011.

BRASIL. Plano Nacional de Prevenção e Erradicação do Trabalho Infantil e Proteção do Adolescente Trabalhador (2019-2022). 2019.

BUCCI, Maria Paula Dallari. Fundamentos para uma teoria jurídica das políticas públicas. São Paulo: Saraiva, 2013.

BUSTELO, Eduardo S. EI recreo de la infancia: Argumentos para otro comienzo. Buenos Aires: Siglo Veintiuno Editores, 2011.

CERQUEIRA-SANTOS, Elder (coordenador da pesquisa). O perfil do caminhoneiro no Brasil. Brasil: Childhood, 2010.

CERQUEIRA-SANTOS, Elder (coordenador da pesquisa). O perfil do caminhoneiro brasileiro. Brasil: Childhood, 2015.

CERQUEIRA-SANTOS, Elder (pesquisador responsável). Vítimas da Exploração Sexual de Crianças e Adolescentes. Brasil: Childhood, [s.d.].

CONTRERAS, Mariana Margutti. Exploração sexual na Amazônia: uma abordagem sóciojurídica. 2015. 215 f. Tese (Doutorado em Direito), Programa de Pós-Graduação em Direito, Universidade Estácio de Sá, Rio de Janeiro, 2015.

CORGOZINHO, Juliana Pinto. Análise do ambiente de vulnerabilidade social no contexto da exploração sexual comercial infanto-juvenil. 2010. 144 f. Dissertação (Mestrado em Ciências do Ambiente), Programa de Mestrado em Ciências do Ambiente, Fundação Universidade do Tocantins, Palmas, 2009.

CUSTÓDIO, André Viana. As atribuições dos Conselhos de Direitos da Criança e do Adolescente para Controle e Efetivação de Políticas Públicas. In: COSTA, Marli Marlene Moraes; LEAL, Monia Clarissa Hennig (Orgs.). Direitos Sociais e Políticas Públicas: Desafios Contemporâneos. Tomo 15. Santa Cruz do Sul: Edunisc, 2015.

CUSTÓDIO, André Viana. Teoria da proteção integral: pressupostos para a compreensão do direito da criança e do adolescente. Revista do Direito: Revista do programa de pós-graduação do mestrado e doutorado, Santa Cruz do Sul, n. 29, p. 22-43, jan./jun. 2008. 
CUSTÓDIO, André Viana; MOREIRA, Rafael Bueno da Rosa. Exploração Sexual Comercial de Crianças e Adolescentes: Reflexões Contemporâneas no Contexto do Brasil, da Argentina e do Uruguai. Curitiba: Multideia, 2015.

CUSTÓDIO, André Viana; MOREIRA, Rafael Bueno da Rosa. Estratégias municipais para o enfrentamento da exploração sexual comercial de crianças e adolescentes. In: XXVII Encontro Nacional do CONPEDI, 27, 2018, Salvador. Anais eletrônicos. Salvador: UFBA, 2018.

CUSTÓDIO, André Viana; MOREIRA, Rafael Bueno da Rosa. Participação política e cidadania no Brasil: exercício da cidadania plena por meio da efetivação da educação de crianças e adolescentes. Revista Meritum, Belo Horizonte, n. 1, v. 14, p. 279-300, jun./dez. 2019.

DILACIO, Graciela; GIORGI, Victor; VARELA, Carlos. Las representaciones sociales acerca de la Explotación Sexual Comercial de Niños, Niñas y Adolescentes y su relación con los paradigmas vigentes en el campo de la infancia y la adolescencia. Psicología, Conocimiento y Sociedad, Montevideo - Uruguay, v. 2, n. 1, p. 170-200, mayo 2012.

FLORES, Joaquín Herrera. A (re)invenção dos direitos humanos. Florianópolis: Fundação Boiteaux, 2009.

GORCZEVSKI, Clovis. Direitos humanos, educação e cidadania: conhecer, educar, praticar. Santa Cruz do Sul: Edunisc, 2009.

LEAL, Maria Lúcia Pinto; LEAL, Maria de Fátima Pinto (Organizadores). Pesquisa sobre Tráfico de Mulheres, Crianças e Adolescentes para fins de Exploração Sexual Comercial - PESTRAF: Relatório Nacional - Brasil. Brasília: CECRIA, 2002.

LIMA, Fernanda da Silva. Crise humanitária internacional e os direitos das crianças migrantes ou refugiadas: uma análise da opinião consultiva $n^{\circ} 21$ da Corte Interamericana de Direitos Humanos. Revista do Direito: Revista do Programa de Pós-graduação do Mestrado e Doutorado, Santa Cruz do Sul, v.1, n. 51, p. 87-107, jan./abr. 2017.

LIMA, Miguel Moacyr Alves. O Direito da Criança e do Adolescente: Fundamentos para uma abordagem principiológica. 2001. 479 f. Tese (Doutorado em Direito), Programa de Pósgraduação em Direito, Universidade Federal de Santa Catarina, Florianópolis, 2001.

LIMA, Rafaela Preto de; MOREIRA, Rafael Bueno da Rosa. O planejamento de ações e estratégias para o enfrentamento da violência intrafamiliar na infância pelos Conselhos Municipais de Direitos da Criança e do Adolescente. Revista Científica do UniRios, Paulo Afonso, n. 23, p. 307-321, jan. 2020.

LONDOÑO, Nora; et al. Factores causales de la explotación sexual infantil en niños, niñas y adolescentes en Colombia. El Ágora USB, Medellín - Colombia, v. 15, n. 1, p. 241-254, ene./jun. 2015.

LOPES, Remy Damasceno. A ESCCA e a lei: Encontros e Despedidas. 2009. $178 \mathrm{f}$. Dissertação (Mestrado em Psicologia), Programa de Pós-graduação em Psicologia Social, Universidade Estadual do Rio de Janeiro, Rio de Janeiro, 2009. 
MORAES, Keila. Uma Experiência Etnográfica de Fronteira: exploração sexual comercial de crianças e jovens na Tríplice Fronteira entre Argentina, Brasil e Paraguai. 2009. 159 f. Dissertação (Mestrado em Psicologia), Programa de Pós-graduação em Psicologia, Universidade Federal de Santa Catarina, Florianópolis, 2009.

MOREIRA, Rafael Bueno da Rosa Moreira. As estratégias e ações de políticas públicas para a erradicação da exploração sexual comercial nos municípios brasileiros no contexto jurídico e político da teoria da proteção integral dos direitos da criança e do adolescente. 2020. 291 f. Tese (Doutorado em Direito), Programa de Pós-Graduação em Direito. Universidade de Santa Cruz do Sul - Unisc, Santa Cruz do Sul, 2020.

MOREIRA, Rafael Bueno da Rosa; CUSTÓDIO, André Viana. O papel das políticas públicas na promoção de ações de sensibilização sobre violência sexual contra crianças e adolescentes. Revista Jurídica Direito e Paz, Lorena, n. 41, ano XII, p. 123-144, jun./dez. 2019.

MOREIRA, Rafael Bueno da Rosa; CUSTÓDIO, André Viana. A Influência do Direito Internacional no Processo de Erradicação do Trabalho Infantil no Brasil. Revista Direitos Fundamentais e Democracia, Curitiba, n. 02, v. 23, p. 178-197, mai./ago. 2018.

MOREIRA, Rafael Bueno da Rosa; CUSTÓDIO, André Viana. A garantia do direito à educação de crianças e adolescentes no contexto das políticas públicas brasileiras. Revista Brasileira de Políticas Públicas, Brasília, n. 01, v. 5, p. 224-245, jan./jun. 2015.

MUJICA, Jaris; CAVAGNOUD, Robin. Mecanismos de explotación sexual de niñas y adolescentes en los alrededores del puerto fluvial de Pucallpa. Anthropologica del Departamento de Ciencias Sociales, San Miguel - Perú, v. 29, n. 29, p. 91-110, dec. 2011.

ORDÓÑEZ, Leidy Bibiana Camacho; GONZÁLEZ, Maria Angélica Trujillo. La explotación sexual comercial infantil: una ganancia subjetiva. Revista Latinoamericana de Ciencias Sociales, Niñez y Juventud, Manizales - Colombia, v. 7, n. 2, p. 1.009-1.025, 2009.

ONU. A convenção sobre os direitos das crianças. 1989. Disponível em: http://www.planalto.gov.br/ccivil_03/decreto/1990-1994/D99710.htm. Acesso em: 10 mar. 2020.

OIT. Convenção 138 sobre a idade mínima de admissão ao emprego. 1973. Disponível em: http://www.planalto.gov.br/ccivil_03/decreto/2002/d4134.htm. Acesso em: 15 mar. 2020.

OIT. Convenção 182 sobre a proibição as piores formas de trabalho infantil e ação imediata para sua eliminação. 1999. Disponível em: http://www.planalto.gov.br/ccivil_03/decreto/d3597.htm. Acesso em: 15 dez. 2020.

REIS, Suzéte da Silva. Educação em Direitos Humanos: Perspectivas de promoção e defesa dos direitos das crianças e adolescentes. In: PES, João Hélio Ferreira (coordenador). Direitos Humanos: Crianças e Adolescentes. Curitiba: Juruá, 2010.

ROSSATO, Luciano Alves; LÉPORE, Paulo Eduardo. A tutela coletiva dos direitos fundamentais da criança e do adolescente trabalhadores. In: VERONESE, Josiane Rose Petry; 
ROSSATO, Luciano Alves; LÉPORE, Paulo Eduardo (Coordenadores). Estatuto da Criança e do Adolescente: 25 anos de desafios e conquistas. São Paulo: Saraiva, 2015.

SANTOS, Danielle M. Espezim dos Santos; VERONESE, Josiane Rose Petry. A eficácia jurídica dos direitos fundamentais sociais de crianças e adolescentes. In: VERONESE, Josiane Rose Petry; ROSSATO, Luciano Alves; LÉPORE, Paulo Eduardo (Coordenadores). Estatuto da Criança e do Adolescente: 25 anos de desafios e conquistas. São Paulo: Saraiva, 2015.

SCHMIDT, João Pedro. Para entender as políticas públicas: aspectos conceituais e metodológicas. In: REIS, Jorge Renato dos; LEAL, Rogério Gesta (organizadores). Direitos Sociais e Políticas Públicas: Desafios Contemporâneos. Tomo 8. Santa Cruz do Sul: Edunisc, 2008 .

SCHMIDT, João Pedro. A orientação ativa nas políticas públicas: condições e diretrizes para a transformação social. 2016 (não publicado).

SILVA, Christian L.; SOUZA-LIMA, José E. Políticas públicas e indicadores para o desenvolvimento sustentável, São Paulo, 2010.

SILVEIRA, Mayra; VERONESE, Josiane Rose Petry. Acesso à Justiça e Justiça da Infância e da Juventude: o juiz, o promotor de justiça, os serviços auxiliares e o advogado. In: VERONESE, Josiane Rose Petry (Coordenadora). Direito da Criança e do Adolescente: Novo Curso - Novos Temas. Rio de Janeiro: Lumen Juris, 2017.

SOUZA, Celina. Políticas Públicas: uma revisão de literatura. Revista Sociologias. Porto Alegre. July/dec-2006.

SOUZA, Ismael Francisco de; CUSTÓDIO, André Viana. Conselhos de Direitos da Criança e Adolescente: Uma perspectiva a partir do poder local. Revista Científica da Fasete, Paulo Afonso, a. 12, n. 19, p. 172-186, nov. 2018.

SUBIRATS, Joan; et al. Análisis y gestión de políticas públicas. Barcelona: Ariel, 2008.

TODOS PELA EDUCAÇÃO. Anuário Brasileiro da Educação Básica. Editora Moderna: São Paulo, 2014.

VERONESE, Josiane Rose Petry. O Estatuto da Criança e do Adolescente: Um Novo Paradigma. In: VERONESE, Josiane Rose Petry; ROSSATO, Luciano Alves; LÉPORE, Paulo Eduardo (Coordenadores). Estatuto da Criança e do Adolescente: 25 anos de desafios e conquistas. São Paulo: Saraiva, 2015a.

VERONESE, Josiane Rose Petry. Adolescente autor de ato infracional sob a perspectiva da intersetorialidade. Revista do Direito: Revista do Programa de Pós-graduação do Mestrado e Doutorado, Santa Cruz do Sul, n. 47, p. 125-143, set./dez. 2015 b.

VERONESE, Josiane Rose Petry; LEME, Luciana Rocha. A Política de Atendimento. In: VERONESE, Josiane Rose Petry (Coordenadora). Direito da Criança e do Adolescente: Novo Curso - Novos Temas. Rio de Janeiro: Lumen Juris, 2017. 
VILLAMIZAR, Raquel Méndez; BETANCUR, Mauricio Rojas; MORENO, Diana Lucia. Explotación sexual comercial infantil: las rutas de vida del maltrato. Investigación \& Desarrollo, Barranquilla - Colombia, v. 20, n. 2, p. 450-471, jul./dec. 2012.

Data de Submissão: 05/05/2020

Data de Aceite: 29/07/2020 